\title{
Optical properties of native and coagulated lamb brain tissues in vitro in the visible and near-infrared spectral range
}

\author{
Korhan ÖZER ${ }^{\mathrm{a}}$, Özgüncem BOZKULAK ${ }^{\mathrm{a}}$, Haşim Özgür TABAKOĞLU ${ }^{\mathrm{a}}$, Adnan KURT ${ }^{\mathrm{b}}$, \\ Murat GÜLSOY*a \\ ${ }^{a}$ Biophotonics Lab., Institute of Biomedical Engineering, Boğaziçi University, Istanbul, Turkey \\ ${ }^{b}$ Department of Physics, Koç University, Istanbul, Turkey
}

\begin{abstract}
The aim of this study was to estimate optical properties $\left(\mu_{\mathrm{a}}, \mu_{\mathrm{s}}, \mu_{\mathrm{t}}, \mu_{\mathrm{s}}{ }^{\prime}, \tau, \alpha, \mathrm{g}\right.$ ) of native and coagulated $\left(\right.$ at $45^{\circ} \mathrm{C}, 60^{\circ} \mathrm{C}$, $80^{\circ} \mathrm{C}$ ) lamb brain tissues in visible and near-infrared spectral range in vitro. Optical properties of cerebellum, brainstem, cortical (grey matter), and sub-cortical regions (white matter) of frontal lobe tissues of lamb brain were estimated during this study. Diffused transmittance $\left(T_{d}\right)$, diffused reflectance $\left(R_{d}\right)$, total reflectance $\left(R_{t}\right)$ and total transmittance $\left(T_{t}\right)$ were measured with single integrating sphere method. Data were processed with software (CAL-g3) developed in Biophotonics Laboratory in the Institute of Biomedical Engineering, Bogazici University. As a result, it was stated that both $\mu_{\mathrm{a}}$ and $\mu_{\mathrm{s}}$ values of tissues increased as temperature increases. Also scattering coefficients decreased with the increasing wavelength for all tissue types due to increase in Mie scattering.
\end{abstract}

Keywords: Absorption, integrating sphere, light-tissue interaction, scattering.

\section{INTRODUCTION}

Due to increasing medical use of light-based devices, emitting energy at different wavelengths, evaluation of optical properties of biological tissues become important [1]. When light interacts with biological tissue, absorption, scattering, and transmission take place due to the optical properties of target tissue as a function of wavelength. Optical properties $\left(\mu_{\mathrm{a}}, \mu_{\mathrm{s}}, \mu_{\mathrm{t}}, \mu_{\mathrm{s}}{ }^{\prime}, \tau, \alpha, \mathrm{g}\right)$ do not only influence distribution and propagation of light in laser-irradiated medium, but also reveal light-tissue interaction mechanism inside biological tissue. For all diagnostic and therapeutic purposes knowledge of optical properties of tissues is crucial for selecting the laser wavelength and also essential for selecting dosimetry in cancer treatments utilizing laser light, photodynamic tumors therapy and photo-thermal treatments [1].

\section{Optical properties of biological tissues}

Biological tissues are optically inhomogeneous and absorbing media, whose refractive index is higher than that of air [2]. Thus, some part of light coming from the source is reflected backward (Fresnel reflection), when the other part goes deep inside the tissue. Multiple scattering and absorption events occur during this penetration, and the light attenuates as it travels. Cellular organelles such as mitochondria are the main scattering substances in various tissues $[2,3]$.

During absorption, intensity of electromagnetic wave is attenuated through the medium. It is a measure of the rate of decrease in the intensity of electromagnetic radiation as it passes through a given substance. Two laws are very important for determination of effects of thickness and concentration on absorption. These are called Beer's law and Lambert's law:

$$
I(z)=I_{0} \times e^{-\mu_{\mathrm{a}} z}
$$

And,

$$
I(z)=I_{0} \times e^{-k^{\prime} \times c \times z}
$$

* gulsoy@boun.edu.tr; tel +90 21235970 26; fax +90 2122575030

Optical Interactions with Tissue and Cells XVII, edited by Steven L. Jacques, William P. Roach, Proc. of SPIE Vol. 6084, 60840P, (2006) $\cdot 1605-7422 / 06 / \$ 15 \cdot$ doi: 10.1117/12.646077 
In those formulas, $\mathrm{z}$ is the optical axis and $\mathrm{I}(\mathrm{z})$ is the intensity at a distance $\mathrm{z}$. $\mathrm{I}_{0}$ is the incident light intensity, $\mu_{\mathrm{a}}$ is the absorption coefficient of the medium, $\mathrm{k}^{\prime}$ is internal parameters other than concentration and $\mathrm{c}$ is concentration $[2,3,4]$. So those two laws describe the same behaviour of the absorption, they are also known as Lambert- Beer's law:

$$
z=\frac{1}{\mu_{\mathrm{a}}} \times\left[\ln \left(\frac{I_{0}}{I(z)}\right)\right]
$$

Scattering of light occurs as a direct result of the interaction of light with random variations in refractive index or small particles in the medium, resulting in a dispersion of the light in all directions. In particular, scattering results from microscopic and macroscopic constituents such as cellular membranes or refractive index mismatching between intra and extra-cellular fluids, mitochondria, ribosome, fat, globules and collagen fibrils within the extra cellular matrix [2, 5].

\section{Turbid media}

Optical properties are obtained by converting measurements of observable quantities into parameters which characterize light propagation in tissue [6]. Quantitative knowledge of light distribution in biological medium can be achieved from the solution of radiative transfer equation provided that accurate values of basic optical properties of the medium are available. In case of laser energy transport, transfer theory is preferred to Maxwell's equations because of imhomogenity of biological tissue. According to transport theory, the radiance $\mathrm{L}(\mathrm{r}, \mathrm{s})$ of light at position $\mathrm{r}$ traveling in a direction of unit vector $\mathrm{s}$ is decreased by absorption and scattering but it is increased by light that is scattered from s' directions into the direction s. Formulation of transport equation assumes that each scattering particle is sufficiently distant from its neighbours preventing interactions between successive scattering effects [7]. Radiative transport equation which describes the light interaction is [8]:

$$
s \times \nabla L(r, s)=-\mu_{t} \times L(r, s)+\int_{4 \pi} p\left(s, s^{\prime}\right) \times L\left(r, s^{\prime}\right) \times d w
$$

Where $\mu_{\mathrm{t}}$ is attenuation coefficient and $\mathrm{dw}$ is the differential solid angle in the direction of $\mathrm{s}^{\prime}$ and $\mathrm{p}\left(\mathrm{s}, \mathrm{s}^{\prime}\right)$ is the phase function. In most tissues, either scattering or absorption occurs at the same time. This type of media is called turbid media. Their total attenuation coefficient can be expressed by

$$
\mu_{t}=\mu_{a}+\mu_{s}
$$

Where $\mu_{\mathrm{a}}$ is absorption coefficient and $\mu_{\mathrm{s}}$ is scattering coefficient. In turbid media mean free optical paths (penetration depth) of incident photons are determined by $[2,3,8]$,

$$
\begin{aligned}
& \tau=\frac{1}{\mu_{t}} \\
& \mu_{s}{ }^{\prime}=\mu_{s} \times(1-g)
\end{aligned}
$$

$\mu_{\mathrm{s}}{ }^{\prime}$ is called reduced scattering coefficient. $\mathrm{g}$ is called anisotropy factor and it can be explained by average cosine of the scattering angle [7]. g approaches $-1,0,1$ that corresponds highly backward, isotropic, and forward scattering respectively $[3,6,8]$. In some cases, scattering or absorption coefficient can be neglected. Another important parameter is called optical albedo. Albedo a is a dimensionless parameter defined as the ratio of scattering to the sum of scattering and absorption [7].

$$
a=\frac{\mu_{s}}{\mu_{t}}
$$

If $\mathrm{a}=0$, attenuation is exclusively due to absorption but if $\mathrm{a}=1$, only scattering occurs [2]. 


\section{METHODOLOGY}

In the present study, optical properties of native and coagulated brain tissues were estimated at different wavelengths and temperatures. There were three important stages: (1) experimental system design, (2) tissue preparation and (3) estimation of optical properties of tissues. Experimental setup was developed for optical measurements such as diffused transmittance $\left(T_{d}\right)$, diffused reflectance $\left(R_{d}\right)$, total reflectance $\left(R_{t}\right)$ and total transmittance $\left(T_{t}\right)$ which were required for determination of optical properties. After these values were measured, software called CAL-g3 has been used for modeling which finally gave desired tissue characterization values.

\subsection{Experimental system design}

Milla Luce M1000 light source was used in experimental setup. Since light that was emitted from optic illuminator was not collimated enough, liquid fiber guide was mounted on the exit of light source. Liquid fiber guide delivered light through monochromator entrance slit with minimum scattering. DK480 (Digikröm 480 Spectral Products, Florida, USA) monochromator was used in order to get desired wavelength from the exit slit which was than focused on integrating sphere. Monochromator parameters (slit width, wavelength choice and grating number) were controlled by a software Dk-Abi. Lens system was used between fiber and monochromator in order to collect focused light on entrance slit of monochromator. All optical systems that were used in experimental setup were used to get minimum light dissipation.

Light that was emitted from the exit slit of monochromator was focused on integrating sphere by means of optical lenses. Systems for transmittance measurements and reflectance measurements (Fig. 1) were different. Before light reached integrating sphere, it was chopped. Light was focused on external grid of chopper SR540 and it was controlled in terms of frequency. After light passed through chopper, it was again focused on integrating sphere to get transmittance and reflectance measurements. Reflected and transmitted light was measured by a detector with a SR510 (Stanford Research Systems, CA, USA) lock-in amplifier.

Integrated sphere (Labsphere, IS-040-SL, North Sutton, USA) was used to measure the total transmittance, diffuse reflectance and the collimated transmittance values [5]. Tissue was placed between glass plates to prevent dehydration and also to provide mechanical support. Reflected and the transmitted light was detected by a detector with a SR510 lock-in amplifier.

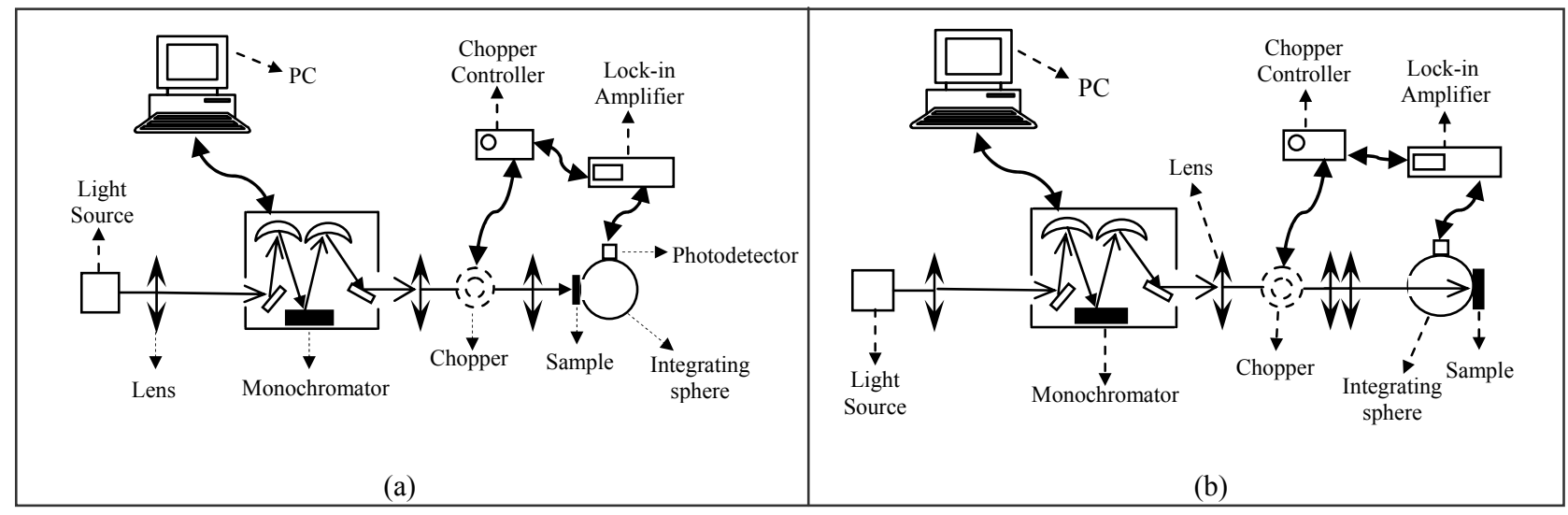

Figure 1: Experimental setup. (a) Sample was placed at the front port of integrating sphere in order to measure $T_{d}$ and $T_{t}$. (b) Sample was placed at the back port of integrating sphere in order to measure $R_{d}$ and $R_{t}$

\subsection{Tissue preparation}

Different parts of native and coagulated lamb brain (cerebellar, brainstem, cortical and sub-cortical regions) tissue were investigated. Tissues were cut into small samples by surgical blade. Those samples were put into a glass tube and squeezed by a metal stick. In sample preparation process, homogenized tissues were poured in the middle of glass slides and then they were closed with a cover slip. Between cover slip and glass slide, there was a polyester film with $125 \mu \mathrm{m}$ thickness. This enabled to give a quite accurate thickness to the tissue drop which was located in between the polyester films. 5 sample slides were prepared for each wavelength measurements. 
Tissue samples were coagulated by using a heat block for 1.5 hours at three different temperatures $\left(45^{\circ} \mathrm{C} \pm 2,60^{\circ} \mathrm{C} \pm 2\right.$, and $80^{\circ} \mathrm{C} \pm 2$ ). After coagulation, measurements of those coagulated tissues were completed individually.

\subsection{Cal-g3 software}

CAL-g3 software that was developed in Biophotonics Laboratory estimates tissues' optical properties. User interface accepts inputs: sample thickness, diffused transmittance, total transmittance, total reflectance and diffused reflectance. As a result, optical properties $\left(\mathrm{g}, \tau, \mu_{\mathrm{s}}, \mu_{\mathrm{a}}, \mu_{\mathrm{t}}, \mu_{\mathrm{s}}^{\prime}\right)$ of biological tissue were determined. Since tissues were between two glass slides, due to glass-tissue interface, measured results should be corrected. CAL-g3 can also makes these correction related to Kottler's formula.

\section{RESULTS}

Optical properties of native and coagulated in vitro lamb brain tissues in visible and near -infrared spectral range were estimated. Differences were compared statistically ( $t$-test and ANOVA tests). Aim of ANOVA test was to investigate significant differences of scattering and absorption coefficients between coagulated and native tissues as temperature changes for same wavelength.

Absorption coefficients of cerebellar tissue, white matter and brainstem tissues were higher within hemoglobin absorption band (Fig. 2,3). Minimum $\mu_{\mathrm{a}}$ was stated at $633-\mathrm{nm}$ for all brain tissues. Significant differences were determined for absorption coefficients of all native and coagulated brain tissues each by means of ANOVA test $\left(\mathrm{F}>>\mathrm{F}_{\text {critical }}\right)$.

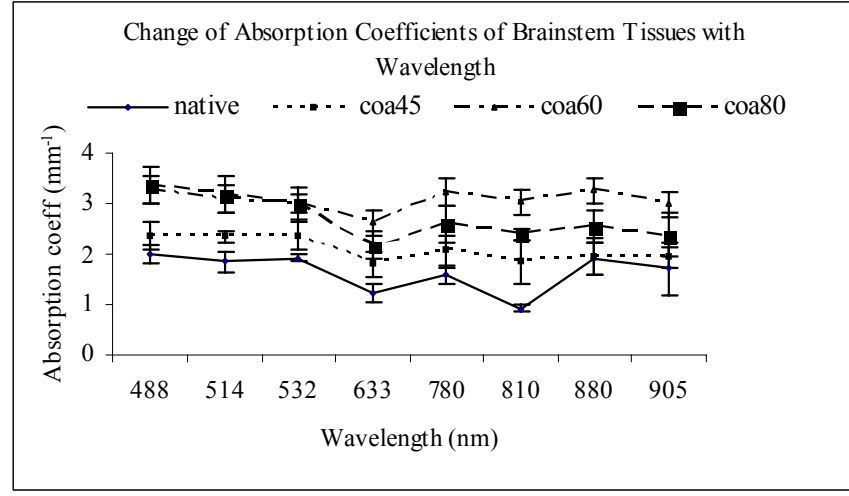

(a)

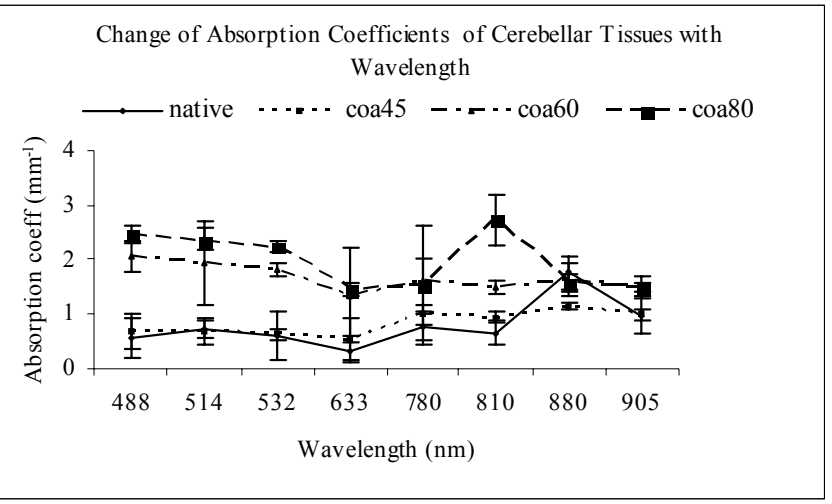

(b)

Figure 2: Absorption coefficients of native and coagulated lamb brain tissues: (a) brainstem tissue, (b) cerebellar tissue.

Scattering coefficients of native and coagulated brainstem tissues were estimated and significant differences were determined by means of ANOVA test. Scattering coefficient values of native and coagulated tissues were significantly different from each other for all wavelengths $\left(\mathrm{F}>>\mathrm{F}_{\text {critical }}\right)$. Also it is evident that as tissue is coagulated, scattering coefficient values increased (Fig. 4, 5). It was said that $\mu_{\mathrm{a}}$ and $\mu_{\mathrm{s}}$ were higher in coagulated tissues than native tissues. Penetration depth of light inside tissue is related to light-tissue interaction. As energy dissipation inside biological tissue increases due to scattering and absorption, penetration depth of light decreases [2]. It was observed that maximum penetration depths of native brain tissues were higher than coagulated tissues (Fig. 6, 7). But at 514-nm, observed penetration depth at $45^{\circ} \mathrm{C}$ was higher than native value for white matter tissue.

Other important optical properties are total attenuation coefficient $\left(\mu_{\mathrm{t}}\right)$, albedo $(\alpha)$, anisotropy factor $(\mathrm{g})$ and reduced scattering $\left(\mu_{\mathrm{s}}\right)$ coefficients. Total attenuation coefficient $\left(\mu_{\mathrm{t}}\right)$ affects penetration depth of light into the tissue. Depth of light through native biological tissues are higher than coagulated ones at all wavelengths and temperatures. Albedo values of all tissues were between 0 and 1, but closer to 1 for all wavelengths and temperatures. Scattering of light was considerably higher than absorption for both native and coagulated tissues. 


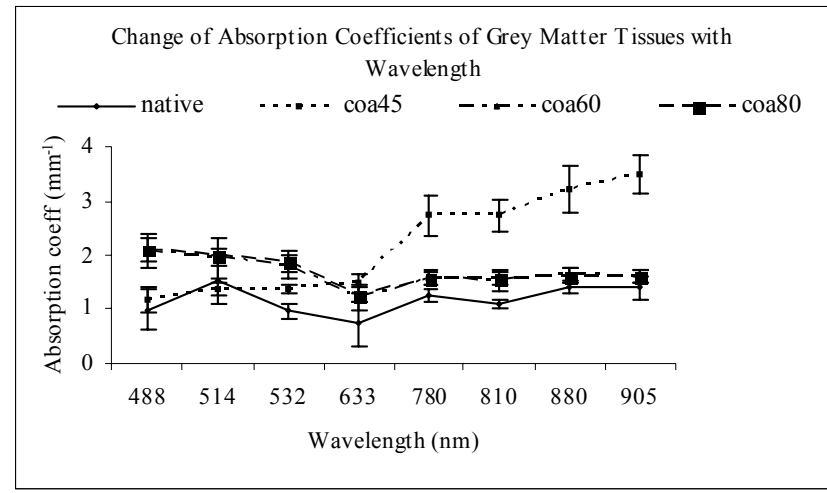

(a)

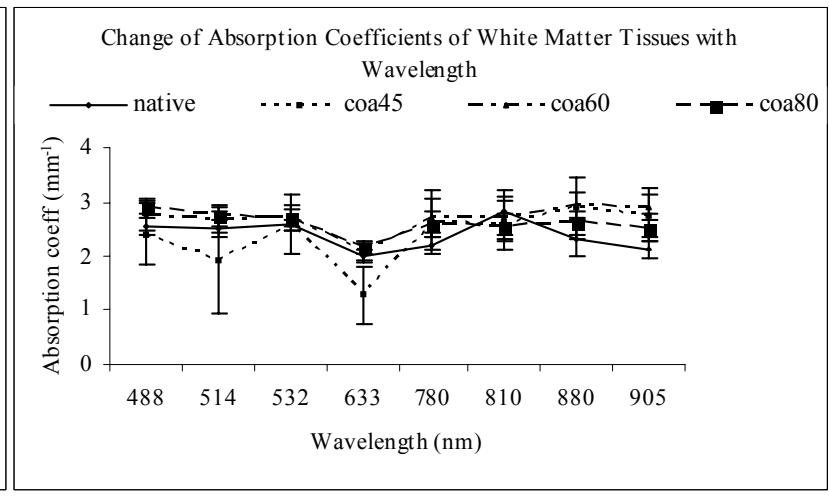

(b)

Figure 3: Absorption coefficients of native and coagulated lamb brain tissues: (a) grey matter tissue, (b) white matter tissue.

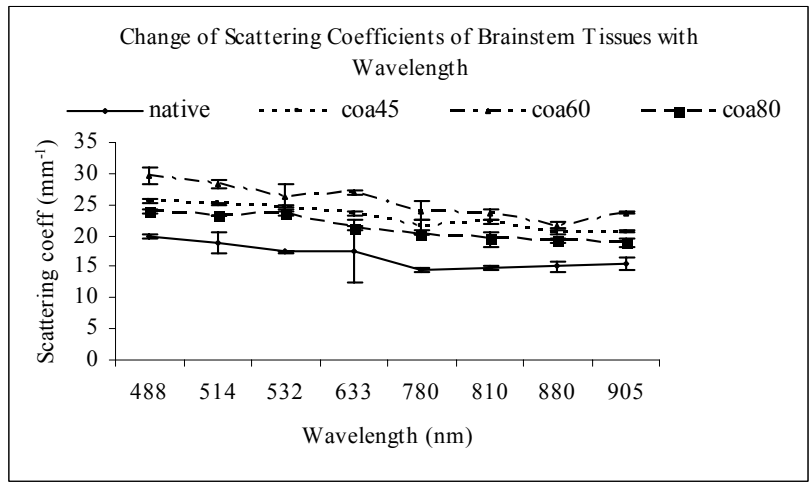

(a)

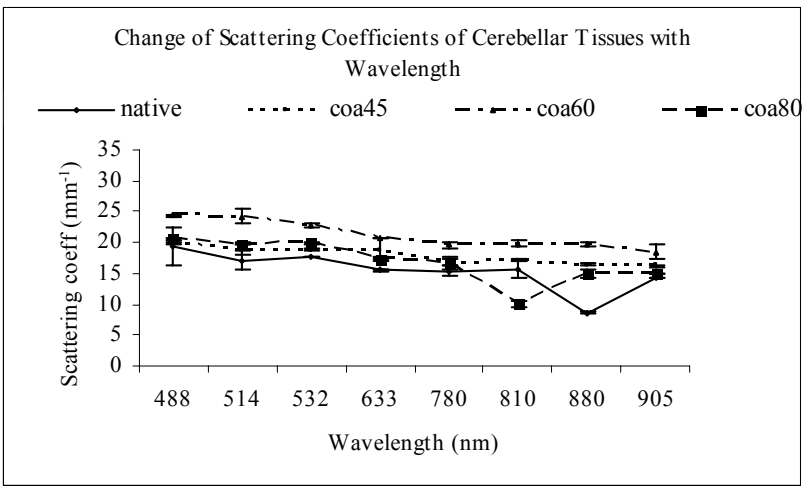

(b)

Figure 4: Scattering coefficients of native and coagulated lamb brain tissues: (a) brainstem tissue, (b) cerebellar tissue.

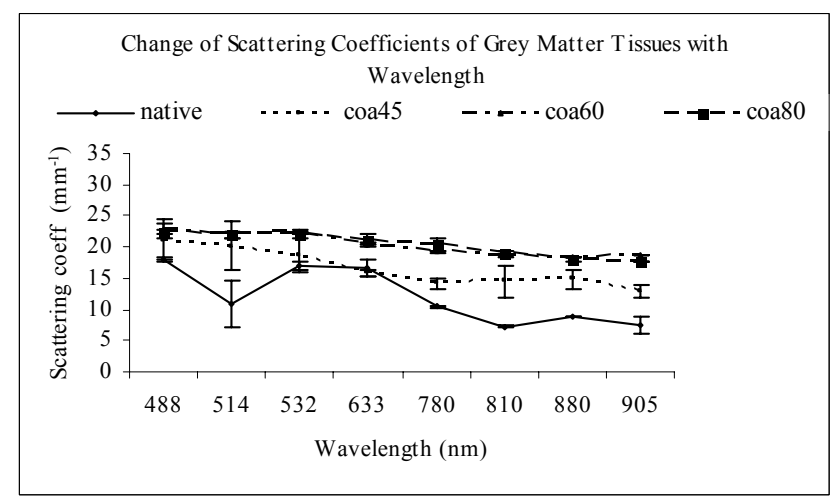

(a)

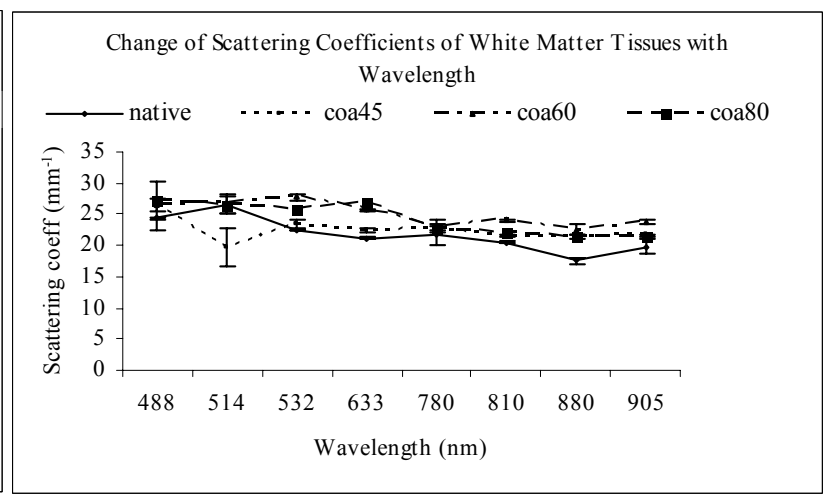

(b)

Figure 5: Scattering coefficients of native and coagulated lamb brain tissues: (a) grey matter tissue, (b) white matter tissue. 


\section{DISCUSSION}

Optical properties of native and coagulated lamb brain tissues within visible and near-infrared spectrum of light were estimated in vitro in this study. Absorption coefficients of native cerebellar tissue, brainstem, white matter and grey matter tissues were found higher for shorter wavelengths (488-nm, 514-nm and 532-nm) related to hemoglobin absorption window [4]. It was reported in literature that as wavelength increased, absorption coefficients decreased in red region (600-700-nm) and red to NIR [4]. In this study, at 633-nm, maximum penetration depth was observed in visible light spectrum.

There are different researches about absorption coefficients after coagulation in literature. Roggan et al concluded that $\mu_{\mathrm{a}}$ was not changed after coagulation [9]. However Yaroslavsky et al stated that $\mu_{\mathrm{a}}$ increased due to thermal effects [10]. In this study, there were increases in $\mu_{\mathrm{a}}$ values (Fig. 2,3). Thus, results in this study were closer to reports of Yaroslavsky et al. For example when grey matter and cerebellar tissue are concerned, at 514-nm native grey matter and cerebellar tissue absorption coefficients were higher than the ones coagulated at $45^{\circ} \mathrm{C}$ (Fig. 2a, 3a). Hyperthermia begins between $43-45^{\circ} \mathrm{C}$.

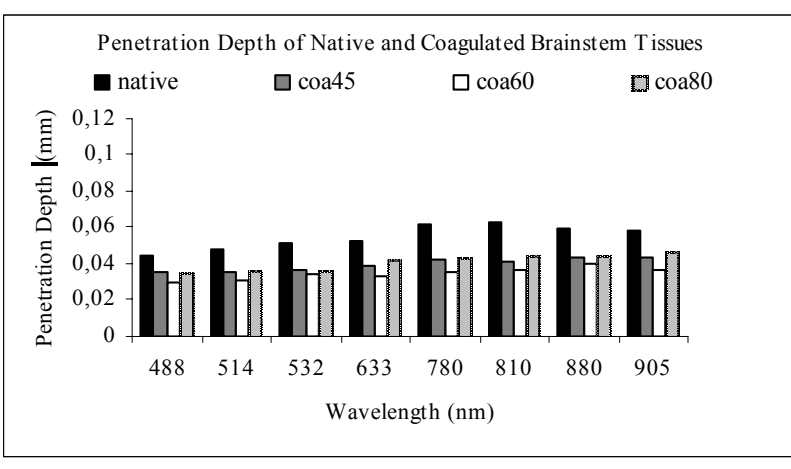

(a)

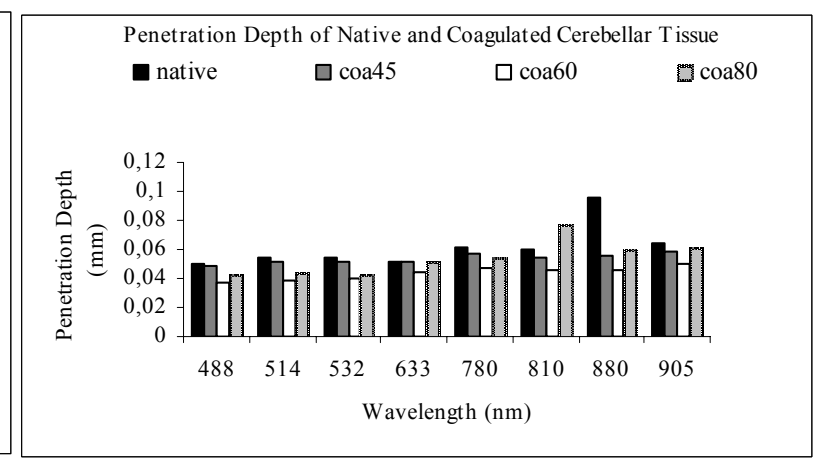

(b)

Figure 6: Penetration depths of native and coagulated lamb brain tissues. (a) brainstem tissue, (b) cerebellar tissue.

However in case of hyperthermia, it was stated that denaturation of macromolecules do not start. Since, there is no structural change observed at this temperature, change in $\mu_{\mathrm{a}}$ at this temperature could not be same as at $60^{\circ} \mathrm{C}$ and $80^{\circ} \mathrm{C}$. Results about absorption coefficients of all tissues were reasonable. Because, as temperature increases, cytoplasmic compounds of tissues such as high number of nerve cells for grey matter or axonal structures typical for white matter, changed after coagulation in response to heat-induced protein denaturation due to their thermal vulnerability [10].

Average scattering coefficient of tissue depends on factors such as the relative refractive index between the scattering objects and their surrounding media, size and shape of the objects and densities of scatterers. Therefore, changes in wavelength-dependence of the scattering coefficient with temperature are more likely to be governed by morphological changes. Scattering coefficients have a tendency of decreasing as wavelength increased for all tissues at all temperature values generally (Fig. 4,5). These findings may be explained by decrease in rayleigh scattering and increase in mie scattering with increase of wavelength [10].

During coagulation process, increase in temperature causes considerable tissue shrinkage due to loss of water. It leads to condensation, collagen swelling and homogenization of vessel walls. As water loss in tissue increases, density of chromophores and scattering imhomogenities also increases, which in turn makes tissue optically denser [2]. Thus, scattering coefficients in this study drastically increased compared to native tissues. [10,11]. 


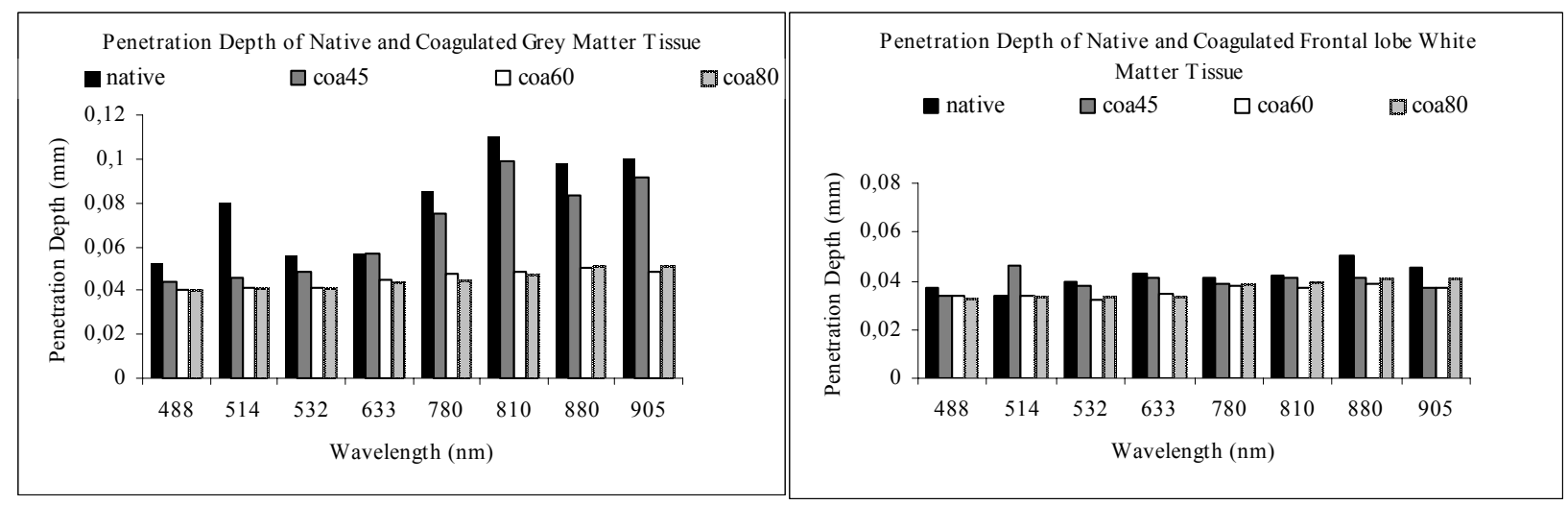

(a)

(b)

Figure 7: Penetration depths of native and coagulated lamb brain tissues. (a) grey matter tissue, (b) white matter tissue

However, this increase was not proportional to temperature increase. It was observed that scattering coefficient values of white matter tissue were higher than grey matter tissue values for all temperatures. This can be explained by higher density of myelin in white matter which increases scattering [1].

Concerning similarities of absorption and scattering coefficients of native brain tissues which were examined by $t$-test, significant differences between grey matter and white matter due to their anatomic differences were observed. White matter has water content of $72 \%$ whereas grey mater has $82 \%$. Lipid to protein ratio of these tissues are also important [11].

From the total attenuation coefficients, penetration depth of those wavelengths were estimated (Fig. 6,7). Light can penetrate into native tissues easier than coagulated tissues because of low total attenuation coefficient values. It was stated that, hemoglobin absorption window affected penetration depth due to high absorption for 488, 514 and 532-nm. Even use of saline solution could not remove hemoglobin completely. Penetration depth increases after 633-nm. Since decrease in scattering coefficients due to rayleigh scattering is higher than increase in absorption coefficients, penetration depths at $810-\mathrm{nm}, 880-\mathrm{nm}$ and $905-\mathrm{nm}$ were higher than $633-\mathrm{nm}$.

\section{CONCLUSIONS}

Optical properties $\left(\mu_{\mathrm{a}}, \mu_{\mathrm{s}}, \mu_{\mathrm{t}}, \mu_{\mathrm{s}}{ }^{\prime}, \tau, \alpha, \mathrm{g}\right)$ of native and coagulated (at $45^{\circ} \mathrm{C}, 60^{\circ} \mathrm{C}, 80^{\circ} \mathrm{C}$ ) lamb brain tissues were estimated in this study within visible and near-infrared spectrum of light in vitro . During experimental study, brainstem, cerebellar tissue, white matter and grey matter tissues of lamb brain were used. These properties were estimated due to measured data. After experimental system was set, total transmittance, total reflectance, diffused transmittance and diffuse reflectance values of tissues were measured for both native and coagulated tissues. Data obtained from experiments were used to estimate optical properties of tissues by means of software (CAL-g3).

It is concluded that scattering coefficients of all brain tissues decreased as wavelength increases due to increase in mie scattering and decrease in rayleigh scattering. Also it was stated that as temperature of tissue increased, both absorption and scattering coefficients of tissues increased related to structural changes occur in tissues because of protein denaturation and water loss.

Since albedo values for native and coagulated brain tissues were between 0 and 1 , all media are turbid media. Scattering types were forward scattering for all of native and coagulated tissues due to anisotropy factors $(0<\alpha<1$ and closer to 1$)$.

\section{ACKNOWLEDGEMENTS}

This work was supported by Boğaziçi University Research Fund under Grant BAP04X101 to Murat GULSOY. 


\section{REFERENCES}

1. Eggert, H. R., V. Blazek, "Optical properties of human brain tissue, meninges and brain tumors in the spectral range of 200 to 900nm," Congress of Neurological Surgeons, vol: 21, no: 4, 1987.

2. $\quad$ Niemz, M. H., Laser-Tissue Interactions, Springer-Verlag, Berlin, Heidelberg, 1996.

3. Tuchin, V., "Tissue Optics: Light scattering methods and instruments for medical diagnosis," International Society for Optical Engineering, Washington, USA, 2000.

4. Gülsoy, M., Biophotonics, BM583 lecture notes, Istanbul, 2003.

5. Wilson, B. C., S. L. Jacques, "Optical reflectance and transmittance of tissues: Principles and applications," IEEE Journal of Quantum Electronics, vol: 26, no: 12, 1990.

6. Cheong, W. F., S. A. Prahl, A J Welch., "A review of the optical properties of biological tissues," IEEE Journal of Quantum Electronics, vol: 26, no: 12, 1990.

7. Zaccanti, G., A. Taddeucci, M. Barilli, P. Bruscaglioni., F. Martelli, "Optical properties of biological tissues," SPIE, vol: 2389, pp. 513-521, 1995.

8. Prahl, S. A, "Light transport in tissue," PhD. thesis, University of Texas, Austin, USA, 1988.

9. Sardar, D. K. and L. B. Levy,“Optical properties of whole blood,” Lasers. Med. Sci, vol:13, pp. 106-111, 1988.

10. Yaroslavsky, A. N., P. Schulze, I. V. Yaroslavsky, R. Schober, F. Ulrich, H.J. Schwarzmaier, "Optical properties of selected native and coagulated human brain tissues in vitro in the visible and near infrared spectral range," Phys. Med. Biol., vol: 47, pp. 2059-2073, 2002.

11. Roggan A., O. Minet, C. Shröder, G. Müller, "Measurements of optical tissue properties using integrating sphere technique," Laser-Medizin-Zentrum GmbH, pp. 6-10,1999. 